\title{
The Use of the Adapted Task of Steiner Problem for the Solution of Optimization Problems of Realization of Industrial Enterprises Production
}

\author{
Radik Sh. Sharipov ${ }^{1 *}$, Alexey G. Isavnin ${ }^{2}$ \\ ${ }^{1,2}$ Kazan Federal University, Naberezhnye Chelny Institute of KFU,
}

*1Email: radik@sharipov.com;

\section{Received: 21st October 2017 Accepted: 16th November 2017, Published: 31st December 2017}

\begin{abstract}
An adapted method for solution of the Steiner problem, in order to define the most optimal location of additional customer support depots, for selling industrial products, is considered in the article. The applicability of Steiner problem in the spectrum of solving the issues of products realization, with using additional coefficients of possible variations of the delivery and coefficients of logistic costs, is indicated in the work. The use of adapted method on the example of an industrial enterprise and the possibility of products delivery to neighboring regions(the markets for the enterprise's products), were considered in the article. Comparison of the results with the classical method for solving the Steiner problem was carried out. The need for adjustments, depending on the features of the area, was determined.

The application of adapted method for solving the Steiner problem, when choosing the sales locations for industrial enterprises allows us to optimize expenses, to reduce prime costs, to improve logistics supply chains. This will ultimately increase the competitiveness of products and the business entity as a whole.

The proposed method for solving the Steiner problem with the indicated coefficients will help to increase the organizational and economic efficiency of industrial enterprises.
\end{abstract}

Keywords: Adaptation of the Steiner Problem, Logistic Coefficients, Optimization, Industrial Enterprise, Warehouse

\section{Introduction}

Any industrial enterprise wants to increase the efficiency of its activities, beginning with the supply of raw resources, production stages and ending with the dissemination of the results of production system functioning. At the same time, considering the results (products of manufacturing) an important factor is their disposal. Timely selling confirms the fact of the need of industrial production results for the market. The data of production volumes determine the level of the company's influence on the market as a whole. Due to this, the indicator of the sales volume is an important financial and economic characteristic of the industrial enterprise activity.

When studying the process of products sales, a wellfunctioning logistics network is necessary for ensuring more rapid and efficient supply. At the same time, the introduction of new customer support depots allows to shorten the time of customers waiting for necessary products, to reduce the cost of delivery. The rational choice of the location of such warehouses allows to improve the logistics supply chains, that ultimately will increase the competitiveness of the products and the business entity as a whole.

When choosing the location of customer support depots, it is necessary to take into account the optimal location, in relation to the participants of the regional sales market, the availability and convenience of various logistics routes (rail, road, water, air).

We propose to consider the adaptation of the Steiner method, taking into account the cost rates for determining the optimal location of storage facilities, in relation to the consumers of the manufacturing enterprise.

\section{Materials and Methods}

Consider the application of our methodology on the example of the Naberezhnye Chelny Pipe Plant as part of the holding company "TEMPO". This enterprise is a producer of pipe products, which sells them to large metal trading companies, machine building enterprises, oil and gas and construction industries in Russia, as well as in near and far-abroad countries [1].

In connection with the increase of required volume of pipe products, due to the construction of the Southern Gas Corridor (TANAP and TAP gas pipeline, and the maintenance of the already functioning South Caucasus gas pipeline (Baku-Tbilisi-Erzurum)), the search for new storage locations near real consumers is an urgent problem. Several countries are involved in this project: Turkmenistan, Azerbaijan, Georgia, Turkey and Iran. In each of these countries, the main points of sale have been determined for the following cities: Baku (directly the port of Baku), Tbilisi (Poti port), Erzurum, Turkmenbashi (port), Teheran (Anzali port) [2, 3].

It is necessary to determine the most optimal location of the additional customer support warehouse, which allows the company to cover the sales market of these regions efficiently and to use existing logistics networks.

To cope with this task, we turn to the possibilities of applying the problem, proposed by Jakob Steiner [4]. The task is to connect some specified points to the 
shortest network, and, if necessary, to take into account the possibility of adding additional pointsSteiner points [5], which differ from the initial ones. Examples of solving this problem were considered earlier by different authors [6-9].

We propose a modified algorithm for solving the Steiner problem, with the aim to determine the location of the warehouse for storage and unloading products of an industrial enterprise. We use an additional variable $Q p_{i}$, that determines the logistic characteristics of the chosen locality:

$$
Q p_{i}=d_{i} * S L Z\left(x_{i}\right) * L S_{i}
$$

Where $d_{i}$ is the length of the site;

$\operatorname{SLZ}\left(x_{i}\right)$

- is the function, determining the logistics costs to the cell $\mathrm{x}$ from the initial, $\sum_{i \in T} \operatorname{SLZ}\left(x_{i}\right) \rightarrow \min _{*}^{*}$
$L S_{i}$ $i_{-}$is the number of outgoing logistical routs (from one to four).

The specified variable $Q p_{i}$, using the Steiner problem, assumes a more accurate calculation of the most optimal point of the warehouse location with respect to consumption points.

The initial position of the starting points-cities is defined as the location of the main consumption centers, namely: Naberezhnye Chelny-is the location of the Naberezhnye Chelny Pipe Plant, the manufacturer of the products; Baku -is the center of the sales market in the territory of Azerbaijan; Turkmenbashi-is the center of the sales market in Turkmenistan; Tbilisi - is a center in Georgia; Erzurum -is the location of the market in Turkey (Figure 1).

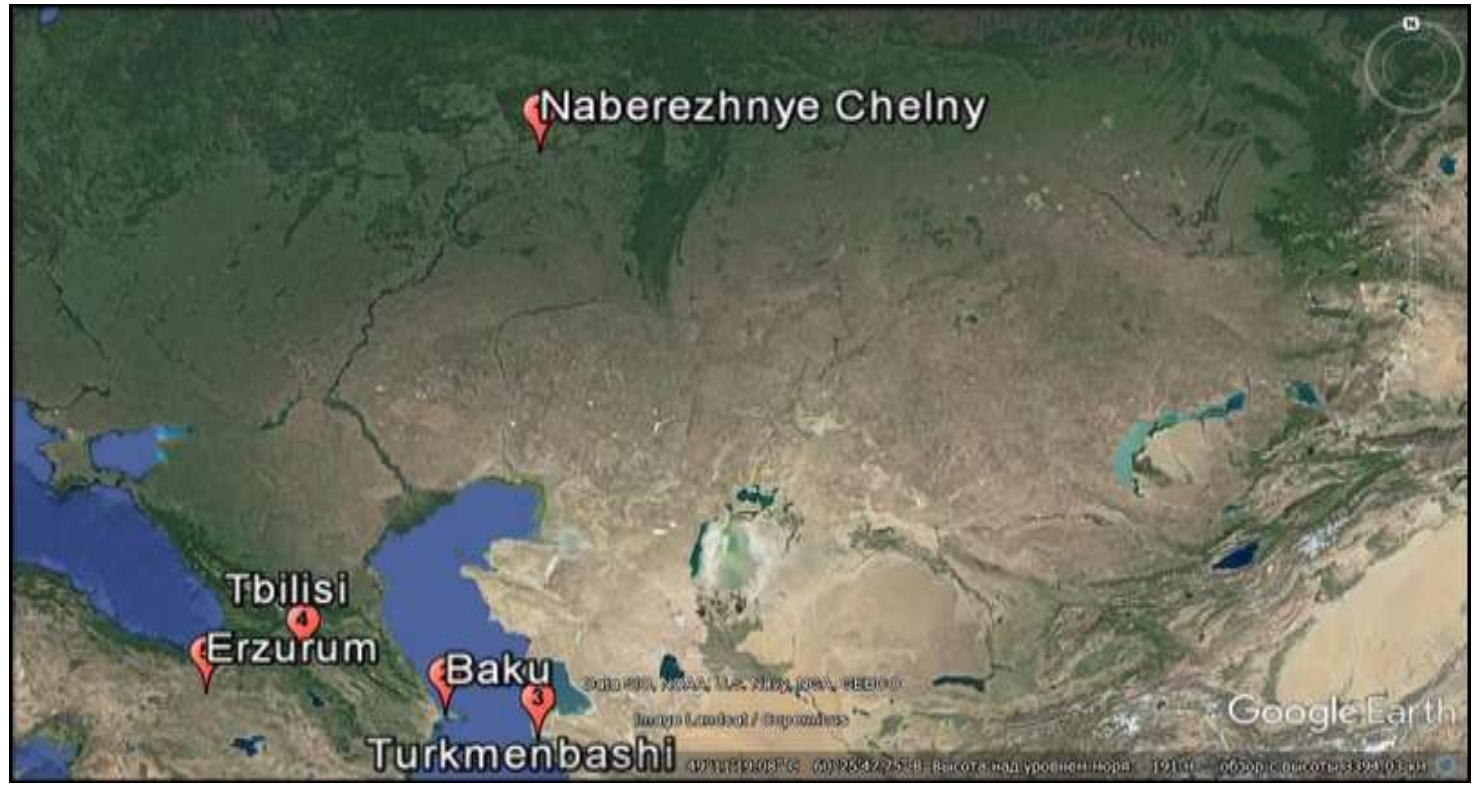

Figure 1. The Location of the Cities on the Google Earth Map

With the aim to define the optimal location of the customer support warehouse on the ground, we apply the adapted Steiner algorithm, taking into account the logistics parameters for choosing the optimal solution.

We use formula (1) to calculate the most attractive cities for the location of warehouse. Considering the location of the "initial" cities near the Caspian Sea and the availability of ports in the cities of Turkmenbashi and Baku (there is an enterprise warehouse), it will be rational to find the location of the object - the port city.
A large number of cities with ports in the Russian Federation, in relation to Naberezhnye Chelny, are located along the Volga: Samara, Saratov, Volgograd, Astrakhan and others.

We use a modification of the Steiner algorithm to find the optimal location of the warehouse and to determine the location of Steiner point. There are five initial vertices-cities. Each of them is indicated by a numerical value from 1 to 5 . Using the classical algorithm, we determined the location of the Steiner point. It coincided with the location of Makhachkala (Figure 2). 


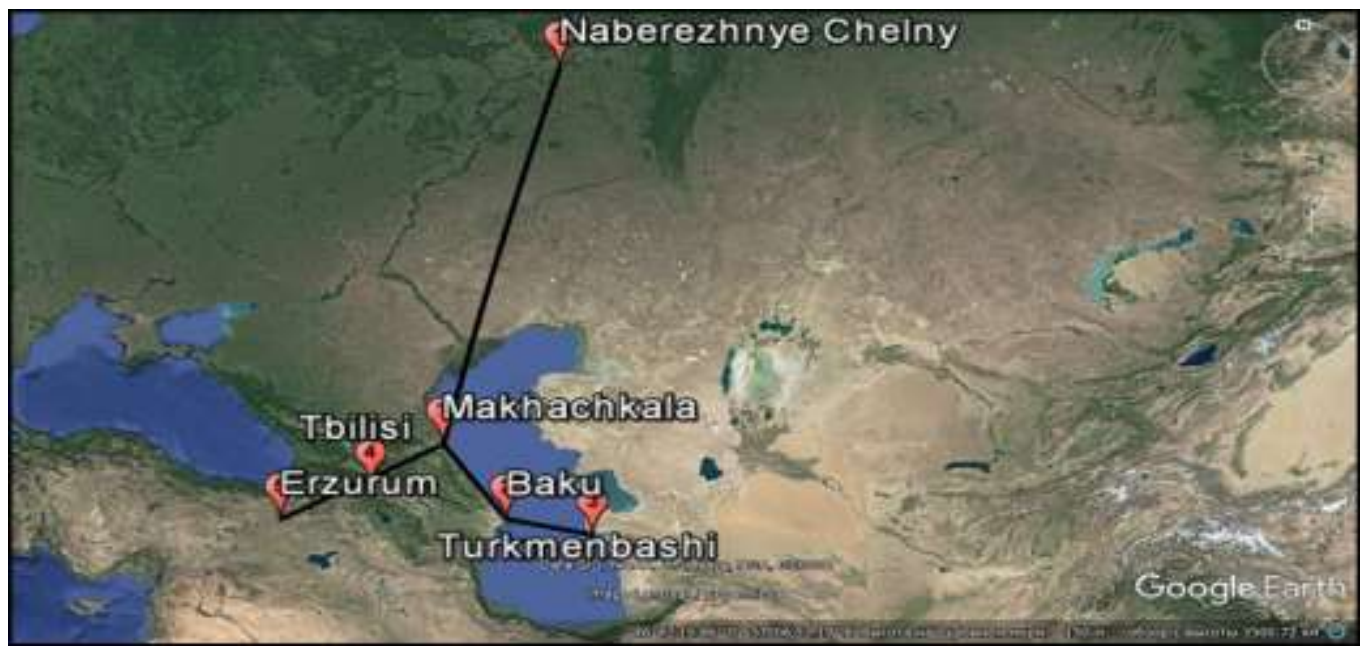

Figure 2 Location of Steiner points in the solution of classical problem

The application of classical algorithm is an effective way to find the best location, in relation to cities, but without considering the availability of access roads to these initial points. Taking into account the possibility of using existing networks of roads and sea routes, the use of geographically advantageous location of Makhachkala, towards the neighboring countries (the sale markets for the products), the choice of this city for the location of warehouse is economically attractive. If it is necessary to use available active logistics networks, the proposal of additional correction, using an adapted algorithm for solving the Steiner problem, will allow to determine the rational location of the warehouse at the current time.

Using our adaptation, proceeding from the fact, that the cost of water logistics is the cheapest in comparison with other ways of delivery, the choice of Steiner point is determined on the basis of the already existing large ports (Figure 3).

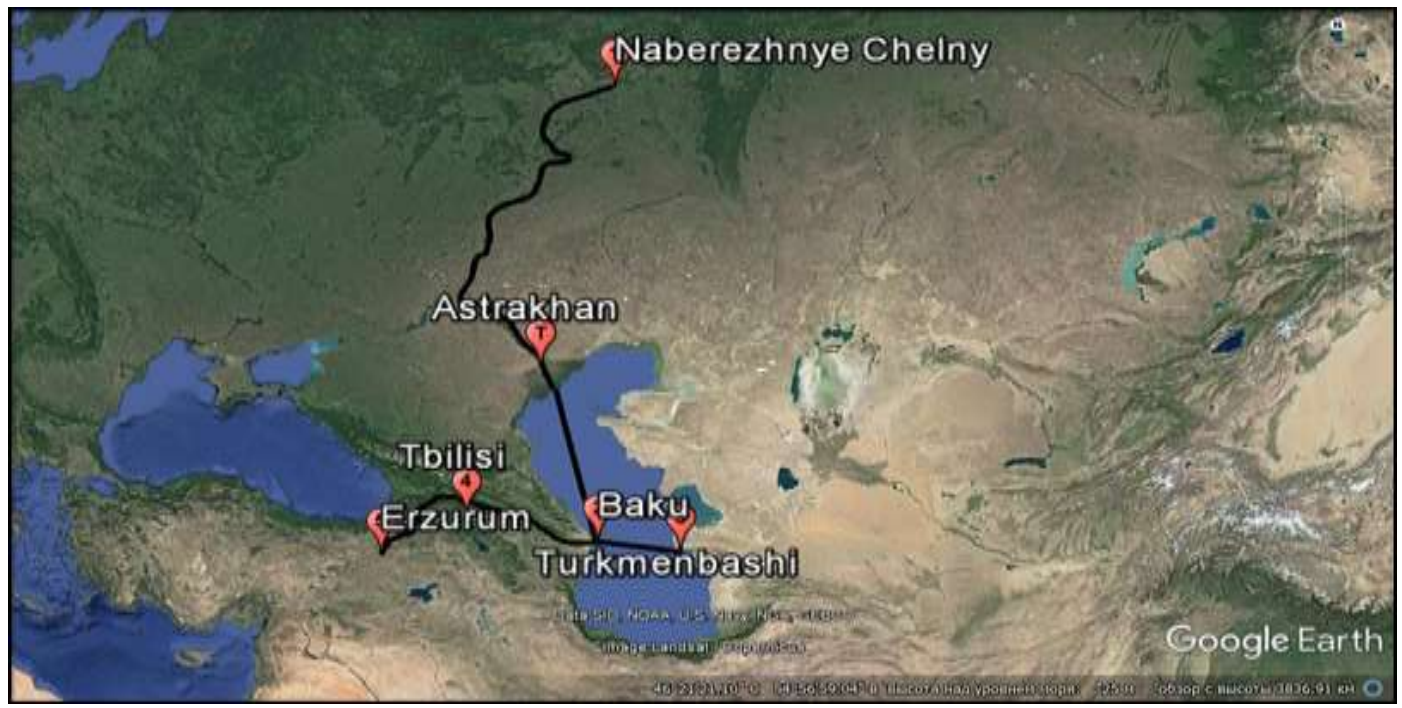

Figure 3. Location of Steiner points in relation to water logistics

\section{Results}

When defining the Steiner point, the cost value $S L Z\left(x_{i}\right)$ from the initial vertex - Naberezhnye Chelny is determined based on the logistics costs. As it is known, water logistics is the most optimal for longdistance cargo transportation of bulky goods. Taking into account the geographical location of Astrakhan, its location near the delta of the Volga River and the Caspian Sea, the selected city is directly the point of Steiner. The number of outgoing logistical routes, in relation to cities along the river, is 3 (water, road and rail logistics). The length of the obtained water route from Naberezhnye Chelny to Astrakhan is $1850 \mathrm{~km}$, by road transport $-1615 \mathrm{~km}$. Transportation via road network is more expensive, than via water. This is due to both the cargo transportation capacity, and the capacity of 1 vehicle: in case of road transportation, 20 tons of cargo can be accommodated for 1 vehicle, the capacity of railroad transport is up to 65 tons, and the capacity of a barge is up to 3,000 tons of cargo. The cost of transportation of 1 truck by the indicated route with a capacity of 20 tons is 75,670 rubles. 
With an average order of 300 tons, the cost of transportation will be 1135050 rubles, including hiring of 15 cars. For 3000 the costs will be 11135 050 rubles. In case of transportation by water, the delivery of full barge to Astrakhan will cost 3,960,000 rubles; and if the barge is not fully loaded, it will be 396,000 rubles (for 300 tons). In a comparative aspect, the difference of $7,175,050$ rubles $(64.4 \%)$ is a significant amount when optimizing total costs.

In the process of transportation to Baku, the costs of road transportation and delivery by sea of 3000 tons will amount to $16,404,000$ rubles, by waterways $9,360,000$ rubles. Savings amount to 7,044,000 rubles $(42.9 \%)$. The reduction of these costs will allow to reduce the costs of production for the manufacturer.

\section{Summary}

Based on the total cost of pipes supply for the markets of Azerbaijan, Turkmenistan, Georgia, the selected location of the warehouse in Astrakhan will reduce the time of order's delivery to the buyer, accelerate the flow of funds from the customer to the manufacturer - the industrial enterprise.

The received solution showed that the application of this method allowed to ensure reduction of costs for transportation of finished products to the sales markets, that, in turn, reduced the cost of pipe production as a whole.

Application of the proposed adaptations of the methods of allowances for the distances between objects on ellipsoid and on sphere for large distances, will allow to increase the accuracy of calculations $[11,12]$.

\section{Conclusions}

The location of new warehouse in Astrakhan provides for the improvement of the logistics supply chain, which makes it possible to increase the competitiveness of products, in relation to local pipe manufacturers. Taking into account the construction of new gas pipelines, the availability of warehouses near these regions positively affects the operational sales of industrial products, thereby supporting the necessary production volumes.

Thus, the use of adapted method for solving the Steiner problem, when choosing the sales locations for industrial enterprises, allows not only to optimize costs and to reduce production costs, but also to improve the logistics supply chain, which ultimately will increase the competitiveness of products and the business entity as a whole.

The proposed method for solving the Steiner problem with the indicated coefficients will help to increase the organizational and economic efficiency of industrial enterprises.

\section{Acknowledgements}

The work is performed according to the Russian Government Program of Competitive Growth of Kazan Federal University.

\section{References}

1. Naberezhnye Chelny Pipe Plant [Electronic resource] // JSC "NaberejnochelninskiyTrubniyZavod" TEM-PO "URL: http://ntz-tempo.ru/ (Access date: 29.05.2017).

2. Trans Anatolian Natural Gas Pipeline project [Electronic resource]// TANAP - URL: http://www.tanap.com/tanap-project (Access date: 01.06.2017).

3. Trans Adriatic Pipeline (TAP) [Electronic resource] // TAP - URL: https://www.tap-ag.com/ (Access date: 01.06.2017).

4. Courant R., Robbins H. What is Mathematics? // An Elementary Approach to Ideas and Methods. Oxford University Press. - 1941.

5. SharipovR.Sh., Isavnin A.G. Application of the modified method for cost optimization in the construction of highways // Scientific review. - 2017. - № 6 - Pp. 136-143.

6. Ivanov A.O., Tuzhilin A.A. The Steiner Ratio Gilbert-Pollak Conjecture Is Still Open // Algorithmica. - 2012. - Vol. 62. - № 1-2- Pp. 630632.

7. Li Y. QoS Multicast Routing Algorithm Based on Crowding Ant Colony Algorithm. // Journal of Computers, North America, 2013. - №8. DOI: 10.4304 / jcp.8.10.2711-2718.

8. Warme D., Winter P., Zachariasen M. Exact algorithms for plane Steiner tree problems: a computational study. - Denmark: University of Copenhagen, 1998. - Pp. 81-116.

9. Yu Hu, Tong Jing, ZheFeng, Xian-Long Hong, Xiao-Dong Hu, Gui-Ying Yan. ACO-Steiner: Ant Colony Optimization Based on Rectilinear Steiner Minimal Tree Algorithm, Journal of Computer Science and Technology, Vol.21. - №1. - Pp. 147152.

10. Du D.Z., Smith J.M., Rubinstein J.H. (Eds.) Advances in Steiner trees. Springer Science \& Business Media, 2013. - Vol. 6 - Pp. 117-135.

11. Isavnin A.G., SharipovR.Sh. Application of the Steiner problem in a spherical coordinate system,taking into account the topographic features of the surface (for road construction) // Economic Analysis: Theory and Practice, 2016. - № 5 (452). Pp. 187-196.

12. SharipovR.Sh., Isavnin A.G. Cost optimization of road construction,with application of Steiner problem on an ellipsoid, using cost rates// Economics and Entrepreneurship, 2016. - №5 (452). - Pp. 573-575. 